\title{
The use of semi-structured interviews for the characterisation of farmer irrigation practices
}

\author{
Jimmy O'Keeffe ${ }^{1}$, Wouter Buytaert ${ }^{1}$, Ana Mijic ${ }^{1}$, Nicholas Brozović ${ }^{2}$, and Rajiv Sinha ${ }^{3}$ \\ ${ }^{1}$ Department of Civil and Environmental Engineering, Imperial College London, London, UK \\ ${ }^{2}$ Robert B. Daugherty Water for Food Institute, University of Nebraska, Lincoln, Nebraska, USA \\ ${ }^{3}$ Department of Earth Sciences, Indian Institute of Technology Kanpur, Uttar Pradesh, India \\ Correspondence to: Jimmy O'Keeffe (j.okeeffe12@imperial.ac.uk)
}

Received: 19 June 2015 - Published in Hydrol. Earth Syst. Sci. Discuss.: 24 August 2015

Revised: 22 April 2016 - Accepted: 26 April 2016 - Published: 12 May 2016

\begin{abstract}
For the development of sustainable and realistic water security, generating information on the behaviours, characteristics, and drivers of users, as well as on the resource itself, is essential. In this paper we present a methodology for collecting qualitative and quantitative data on water use practices through semi-structured interviews. This approach facilitates the collection of detailed information on actors' decisions in a convenient and cost-effective manner. Semi-structured interviews are organised around a topic guide, which helps lead the conversation in a standardised way while allowing sufficient opportunity for relevant issues to emerge. In addition, they can be used to obtain certain types of quantitative data. While not as accurate as direct measurements, they can provide useful information on local practices and users' insights. We present an application of the methodology on farmer water use in two districts in the state of Uttar Pradesh in northern India. By means of 100 farmer interviews, information was collected on various aspects of irrigation practices, including irrigation water volumes, irrigation cost, water source, and their spatial variability. Statistical analyses of the information, along with data visualisation, are also presented, indicating a significant variation in irrigation practices both within and between districts. Our application shows that semi-structured interviews are an effective and efficient method of collecting both qualitative and quantitative information for the assessment of drivers, behaviours, and their outcomes in a data-scarce region. The collection of this type of data could significantly improve insights on water resources, leading to more realistic management options and increased water security in the future.
\end{abstract}

\section{Introduction}

The interactions between humans and water resources are often poorly understood: an issue which can be reflected in the decisions behind water resource planning. While some anthropogenic influences, such as greenhouse gas emissions and land use change, have been incorporated in much of the current modelling and decision-making framework, less work has been carried out on the human-water interface (Nazemi and Wheater, 2015b). This shortfall is seen as a major challenge in earth system modelling (GEWEX, 2012) and consequently decisions on water resource management. Given that human-induced issues of water scarcity affect many parts of the world (Döll et al., 2014; Famiglietti, 2014; Rodell et al., 2009; Voss et al., 2013; Wada et al., 2010), there is a need to understand anthropogenic-hydrological linkages in order to better manage water resources in the future. Socio-hydrology provides a means of supporting sustainable societal development in a changing environment (Montanari, 2015). Indeed, the significance of including so-called soft data has been well documented (see Siebert and Döll, 2010, and Fenicia et al., 2011). Winsemius et al. (2009) argue the importance of including qualitative information to improve model realism; while this may lead to reduced model efficiency, it can help produce a more realistic representation of catchment behaviour. Making use of this "experimental common sense" (Döll and Siebert, 2002) is an important step in more accurately representing anthropogenic water use in models. While this paper is primarily concerned with data collection, the importance of obtaining and using soft, qualitative data is implied. Globally, irrigation water consump- 
tion accounts for some $70 \%$ of total groundwater and surface water withdrawals (Wisser et al., 2008). This figure has increased dramatically over the last 60 years, largely as a result of population growth, market expansion, and technological advances in water abstraction. Consequently, irrigation water use needs to be explored in more detail than non-irrigative demand (Nazemi and Wheater, 2015b).

Representing water use presents many challenges, many of which stem from a lack of data (Gao et al., 2012; Portmann et al., 2010; Nazemi and Wheater, 2015a). This often leads to oversimplification, either in resolution (Döll and Siebert, 2002) or in user behaviour, which can subsequently be reflected in model outputs. For example, irrigation water requirements are often calculated based on the ideal crop water requirement (see Allen et al., 1998, and McKenney and Rosenberg, 1993), giving a false representation of what is actually taking place on the ground - as users will often overor under-irrigate depending on prevailing social, economic, or environmental conditions. Large-scale model outputs or data representations also provide excellent tools for examining water use or resource trends (Döll and Siebert, 2002; Rodell et al., 2009). While such approaches are useful as an overview of large-scale issues, they are inadequate for developing realistic solutions at a meaningful, implementable level. The data collection methods described in this paper are aimed at providing information for more local-scale models and decision making, particularly in instances where such information is scarce. This dearth of information includes both quantitative and qualitative data. In order to come up with suitable options for the use of water, it is important to generate information at a realistic spatial resolution, not only on the water resource itself but also on the behaviours, characteristics, and drivers of its managers and users.

In social sciences and healthcare the collection of both qualitative and quantitative information through interviews is relatively common practice (Barriball and While, 1994; Ellis and Chen, 2013; Fallon, 2008; Gibson, 1998); however, such methods are less used in the fields of earth and engineering sciences. For the purposes of data collection for hydrological studies little guidance exists. In a both time- and resourceconstrained setting the use of semi-structured interviews provides an efficient and effective method for qualitative and quantitative data collection. This is particularly true of datascarce regions, as in our case study, where limited field information exists. According to Calheiros et al. (2000), using an ethnographic methodology is useful in instances where the theory is incomplete and the phenomena are observable and important at a local level. For the most part little room exists for the inclusion of "non-experts" into the application of scientific research methods (Calheiros et al., 2000). The incorporation of local knowledge however can have many advantages, including better defining the research questions and raising locally important, as well as unimportant, factors. Unlike a structured interview which contains a series of set questions asked the same way to all interviewees, a semi- structured interview is organised around a topic guide. The topic guide ensures the main points of interest are satisfied during the interview (Mason, 2002), while still allowing the overall direction to be shaped by the participants' own understanding, so-called experiential or traditional knowledge, of their environment. This naturally highlights issues which are of most importance to the interviewee and allows room to incorporate new themes. Semi-structured interviews can quickly produce rich and detailed data sets (Fallon, 2008) offering an accurate assessment of the characteristics of individuals and phenomena. Importantly, it can also shed light on the drivers of these events and the motivations behind user decisions, providing a valuable contribution to earth systems modelling. Semi-structured interviews allow for the collection of qualitative and quantitative information efficiently and cost effectively, in an unobtrusive and open manner. While qualitative approaches such as semi-structured interviews are widely recognised and regularly applied by social scientists working on water resources, they are scarcely used by natural scientists in the context of hydrology and modelling. In this paper we show how the method can be used for hydrological research; however, we see much greater scope for interdisciplinary dialogue on semi-structured interviews and its broader relevance in addressing hydrological model uncertainties. Aspects of the approach reported herein may differ from traditional methods (see Burnard et al., 2008, and Creswell, 2009), for example in terms of sampling. However, we believe semi-structured interviews provide an effective tool for data collection on water use. In this study, we applied this approach to two districts in the northern Indian state of Uttar Pradesh to study irrigation water use, and the results are presented as a case study in Sect. 3, with the methodology used described in Sect. 2.

\section{Methodology}

\subsection{Study preparation and interview design}

The collection of qualitative and quantitative data in the field requires an understanding of the social nuances that exist in a study region, as well as the relevant existing published research. This knowledge is essential in the planning phase, including the design of the topic guide, around which the semistructured interview is based (Ellis and Chen, 2013). The literature review and pre-fieldwork planning, which should also take practicalities such as logistics and cost into account, help define the main study area and the target interview participants. In this paper we treat the semi-structured interview purely as a tool for the collection of hydrological data in the field. Careful and consistent phrasing of questions in the interview is important and draws on the pre-fieldwork research as well as knowledge of the local characteristics. Questions should be unambiguous and easily understood by interviewees, related to their own experiences, and ethically 
and culturally sensitive, and they should ensure that they assist, rather than impede, the flow of information. In addition, the interviewer must ensure that the questions provide data which will address the research questions appropriately (Mason, 2002). Interviewees may not be able to give a direct answer to a technical question; however, skilfully crafted component questions can be combined to produce the required information (e.g. abstraction rates achieved via depth of water applied and irrigated area).

A significant advantage of semi-structured interviews is the opportunity for previously unknown information to emerge. Participants can be regarded as experts by experience; therefore when sufficient opportunity to speak freely is provided, new and novel information can emerge. This approach allows both quantitative and qualitative data extraction, for example the volume of water a farmer takes from a particular source and their reason for this. This approach can yield considerable benefits in terms of cost whilst ensuring a useful representation of parameters. Semi-structured interviews are traditionally comprised of open-ended questions. The collection of quantitative data, however, is best achieved through direct questions. For this reason the topic guide used in the case study contains both open-ended and direct questions (see Supplement). While acquiring quantitative information in this manner is not as accurate as, for example, metered data, we believe this approach can provide a useful representation of the important parameters and has a place in situations where other measures could be considered unacceptable to the sample or unfeasible in the environment.

\subsection{Sampling}

Sampling comprises an integral part of study design. It allows us to select cases from a wider population, too big to be studied completely, enabling us to generalise the final research conclusions to an entire population, not just to the individual participants of a study (Flick, 2014). This is an important consideration when collecting information which could be used in policy, as any decisions arising from the data should be as applicable as possible to the wider population. The sampling procedure traditionally adopted with semi-structured interviews does not aim to achieve a representative sample. However, a representative sampling was a useful strategy for the purpose of the case study reported herein, in order to produce more universally acceptable results. This is achieved through a combination of sampling techniques. For example, purposive sampling provides a useful starting point by selecting participants who are thought to be information rich. Purposive sampling involves the random selection of sampling units from a part of the population likely to contain the most information on the characteristics of interest to the researcher (Guarte and Barrios, 2006). Purposive sampling allows subjects to be selected based on their characteristics; while this approach is often used to highlight and study extreme or deviant cases, it can allow the researcher to target sample populations which are likely to provide information of most relevance to the research questions. Once a sample group has been identified, randomisation should take place to ensure a representative cross section of the study group is achieved. Prior to undertaking fieldwork it is necessary to set participant inclusion and exclusion criteria, as it is likely that potential interviewees who fall outside the research area interests will be approached. Inclusion and exclusion criteria help promote the best use of available resources.

\subsection{Conducting the interview}

Correct introduction of the study to potential participants is essential when gaining informed consent. This involves a clear and concise explanation of the purpose of the research, what the interview will involve, and how you are going to use and store the information collected. It should also be highlighted that the respondent is under no obligation to answer any of the questions if they do not wish to (Mottram, 2011). This component of the research is important not only in creating the right kind of environment where the interviewee feels they can provide the information, but also in building good rapport with the individual (Rabionet, 2011). The subject of ethics is an important consideration when entering other people's environments and collecting data on their livelihoods. While it is outside the scope of this paper to provide guidelines on ethics, it is strongly recommended that they are taken into account during the planning stage of the study.

Semi-structured interviews may need to be carried out via translator(s). Pre-project training should be provided to translators beforehand to ensure consistency in terms of interview style. In the field, interviews may be conducted in the presence of family members or neighbours. While for practical and cultural reasons it may not be possible to avoid this, care should be taken at all times to address the question to and receive the response from the designated participant, bearing in mind the potential impact others' presence may have on the answers received. It is important that the interview is recorded in as much detail as possible, ideally through a mixture of field notes and a voice recorder. Again, consent should be sought from the interview participant prior to the recording of any conversation. GPS readings of where the interview takes place and any other pertinent locations, for example wells or canal access points, should also be taken, along with photos and samples where applicable. Data should be stored safely and securely following all applicable institutional guidelines. It should be made clear to the participants that their privacy and confidentiality will be maintained to the highest degree possible. 


\subsection{Data processing and analyses}

Following the collection of data, all interviews should be transcribed verbatim. While time-consuming, a full transcription is paramount in avoiding bias introduced through selective data extraction by the researcher, who may have particular themes or research questions in mind. It also ensures that all data remain available for further analyses, rather than what is of interest to the researcher at that time. Reading the transcripts results in various themes emerging from the text, from which a thematic analysis begins. Themes are referred to as codes during the analysis. As the analysis progresses, commonality of codes across interviews may become apparent. However, thematic analysis allows new themes or ideas to constantly emerge. The use of qualitative data analysis software, for example RQDA (Huang, 2014), provides a useful platform for processing large amounts of qualitative data. Words or sections from a discussion are coded, allowing the frequency and relationships across topics to be analysed (Barnes et al., 2013). While the analysis of textual data can be a difficult process, it is made more straightforward using the appropriate software. It is also important to note that that such tools do not analyse the data, which is the task of the researcher; they only make the handling of such data more straightforward (Burnard et al., 2008). This also allows information, both qualitative and quantitative, on each theme to be recalled easily. Once the data have been coded, the dominant themes can be identified. Overviews of the distributions of variables within the database can also be produced. A significant portion of the data collected may also be quantitative and suitable for some statistical analyses and modelling purposes.

\section{Case study - data collection}

\subsection{Study region: the Ganges Basin, northern India}

The Green Revolution has led to enormous gains in agricultural productivity in India, largely through the use of more reliable seeds and improved irrigation technology (Singh, 2000). This has allowed India to become food self-sufficient (Jewitt and Baker, 2007) and has undoubtedly improved life for the majority of rural poor. The Indian Green Revolution has also received much criticism for its environmental and socio-economic impacts. This includes a reduction in India's water resources while becoming one of the most intensely irrigated areas of the world (Rodell et al., 2009; Tiwari et al., 2009; Mueller et al., 2012). However, to correctly investigate water security, field studies and an understanding of the often highly localised spatial variations in water abstraction need to be considered. While the large-scale impacts on water resources are known, the factors influencing irrigation practices on a local level are much less understood. In order to develop realistic and socially acceptable options for water use in the future, this local variability needs to be taken into account.

Uttar Pradesh (UP), located on the plains of the Ganges Basin, is the highest producer of food grains and sugarcane in the country (Hagirath et al., 2011) and the most densely populated (Government of India, 2011). Rice, grown during Kharif (the monsoon season from June to October), and wheat, grown during Rabbi (November to April), are the two most dominant crops (Singh et al., 2011). In the past, the dominant irrigation method in Uttar Pradesh has been via canal, much of which is supplied by the Ganges and Yamuna rivers. However according to Amarasinghe et al. (2009), canal irrigation has declined by approximately $40 \%$ during the last 4 decades, with a 13 -fold increase in irrigation by tube wells.

The following sections comprise a description of a case study in which data were collected through a series of semistructured interviews. This was carried out in a data-scarce region, with the collected information, through mapping and statistical analyses, used to gain a better insight into regional irrigation practices and the motivations of users. Based on irrigation water source information contained within the statistical abstract of Uttar Pradesh (Uttar Pradesh State Planning Institute, 2012), two districts - Jalaun, the highest user of surface water in the state, and Sitapur, one of the highest irrigators in UP using groundwater - were chosen for investigation. The highest was not considered a viable option due to logistical constraints. A map of the study area, along with the interview locations, is presented in Fig. 1.

\subsubsection{Jalaun}

Jalaun is located in the south central region of Uttar Pradesh, and is bounded by the Yamuna River to the north and the Betwa River to the east, covering an area of $4565 \mathrm{~km}^{2}$. It is home to over 1.5 million people (Uttar Pradesh State Planning Institute, 2012). Jalaun receives an average annual rainfall of $811 \mathrm{~mm}$, about $70 \%$ of which falls during the monsoon season of June to August (ICRISAT-ICAR-IRRI, 2012). Approximately 139000 ha of land is irrigated per year using canal water, making it one of the highest users of this resource in the state. While canal water is generally applied through gravity flow along irrigation channels, groundwater is abstracted predominantly via diesel pumps. It was noted that there were approximately 10421 diesel pump sets recorded in 2012 in the district, with electricity powering just 356 units. As there is no restriction on the number of wells that can be drilled or on pump specifications, it is likely that there are many more diesel pumps in use. The main crop grown in the district is wheat, with a total cropped area of 146307 ha. Jalaun is classed as one of Uttar Pradesh's 35 more deprived districts (Ministry of Panchayati Raj, 2014) and is known to be one of the more drought-prone regions of the state (Avtar et al., 2011). 


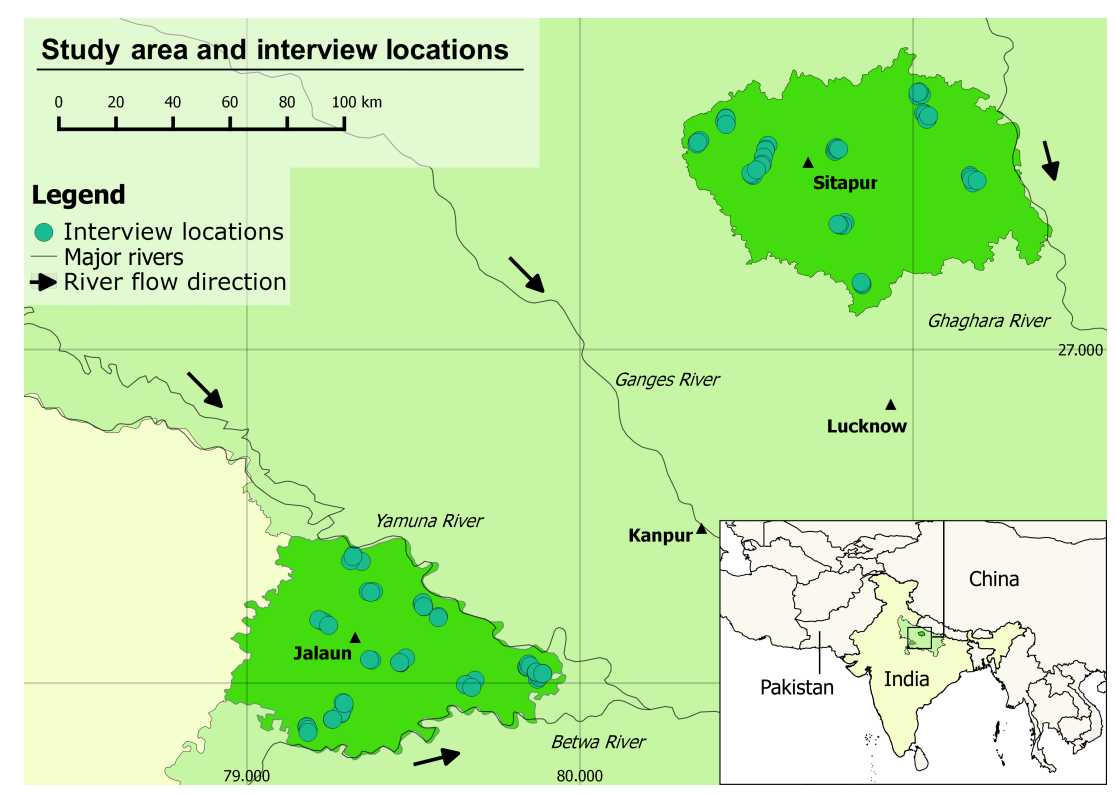

Figure 1. Map of the study region including the locations of the field interviews carried out.

\subsubsection{Sitapur}

Sitapur, also considered one of Uttar Pradesh's less developed districts (Ministry of Panchayati Raj, 2014), is located to the north of the state capital, Lucknow, and has a population of approximately 4.5 million (Uttar Pradesh State Planning Institute, 2012). The average rainfall in Sitapur is $903 \mathrm{~mm}, 66 \%$ of which falls during the monsoon months (ICRISAT-ICAR-IRRI, 2012). On a district scale it is one of the largest irrigators in Uttar Pradesh and supplies its 374445 ha of irrigated land largely using groundwater, with canal water only accounting for 17914 ha. Using electricity for groundwater abstraction in this region is rare, and farmers predominantly use diesel pumps. As with Jalaun, lack of regulations and difficulty in counting wells indicate a larger number of pumps in use across the district. The main crops grown are rice, wheat, and sugarcane, with most farmers carrying out a rice-wheat rotation on their land.

\subsection{Interview design}

The main focus of this study was to investigate farmer irrigation behaviour in the Ganges Basin of northern India and to collect relevant quantitative as well as qualitative information, all of which may be used for informing and driving models. Following a detailed literature review, a methodology employing semi-structured interviews was designed and a topic guide was organised around the following themes:

1. farm and crop information (farm size, soil type, crop type, crop calendar, yield),

2. irrigation practices (number of irrigation events, irrigation volume, irrigation methods),
3. water source (water source reliability, irrigation cost, irrigation method, influences on irrigation, presence of water market, power source, constraints),

4. other (perceptions of challenges faced, potential rationales, changes in water availability, livelihood sustainability).

The topic guide was designed to collect relevant information with as much flexibility as possible, allowing the interview to be shaped by the interviewees' own understandings, the interests of the researcher, and any unexpected themes that emerge. The topic guide used during the interviews is presented (see Supplement). While the contents of the topic guide are presented as questions, they were treated as prompts. This allows the conversation to progress with as much flexibility as possible while still keeping the interviews relevant to the research questions. However, while the aim is to highlight new data through open-ended questions and a fluid interview structure, some direct questions are included, for example relating to farm size or the depth of water.

\subsection{Sampling}

As described, fieldwork was undertaken in two districts, chosen based on their irrigation water source, with Jalaun the highest user of canal water in Uttar Pradesh, and Sitapur irrigating almost exclusively through groundwater. This initial targeted approach was deemed necessary to capture a representative sample of water users, including both conjunctive and groundwater-only users, producing as rich a data set as possible, whilst also considering logistics and other resource constraints, such as time and finances. Following the identification of the fieldwork regions, a list of villages in each 
district was obtained (Government of India, 2011). These were randomised with 15 villages picked as data collection points. Between 3 and 5 interviews were conducted in each of the attended villages, with 50 farmers interviewed in each of the two districts. After approaching a potential interviewee, inclusion and exclusion criteria were used to determine whether or not the participant was eligible. Interview participant inclusion criteria were a farmer who (1) who grew wheat and/or rice, (2) irrigated their crops rather than depended on rain only, (3) had land within approximately $5 \mathrm{~km}$ from the village centre, and (4) had the authority to answer the questions. Participants were excluded if they were (1) too young or did not have the authority to answer the questions, or (2) if their land was too close to a previously interviewed farmer.

\subsection{Data collection - conducting the interview}

The fieldwork team consisted of the researcher, a translator, and a driver. All interviews were conducted through a translator. Potential interviewees were approached when seen in the field. No "gatekeeper", such as a village head or government official, was approached in order to facilitate meetings with participants as it was unnecessary and could have impeded the data collection and potentially impacted on the information received. Once a potential participant was identified, he was approached by the researcher and translator, who made an introduction, described the project, and asked if they would be willing to answer questions. It was made clear that the interviewee was under no obligation to take part if they did not wish to do so and that all information collected would be treated in the strictest confidence. It was also highlighted that if participants had any questions they were free to ask. During the interview the participant was given as much opportunity as possible to expand on topics that were of most interest to them. All interviews were recorded using a dictaphone and field notes, with GPS readings of pertinent locations and photographs taken throughout.

\subsection{Data processing and analyses}

Once data collection was completed, all interviews were transcribed verbatim and uploaded to the qualitative data analysis package RQDA (Huang, 2014) to allow for thematic analyses of the data. During the interviews and while reading the transcripts, a number of themes emerged as being important, for example the cost of irrigation, the reliability of their water source, and the importance of conjunctive surface and groundwater use. These themes were coded to different sections from the transcribed interviews, allowing not only a commonality of themes to emerge across interviews but also unique perspectives to be highlighted. A significant portion of the data collected was quantitative. This allowed for statistical analyses of variables to assess differences in irrigation practices between and within the two districts. These included the volume of water applied $\left(\mathrm{m}^{3} \mathrm{ha}^{-1}\right)$, the volume of water required to produce $1 \mathrm{t}$ of wheat $\left(\mathrm{m}^{3} \mathrm{t}^{-1}\right)$, the cost of wheat irrigation during the growing season $\left(\mathrm{rha}^{-1}\right)$, the crop yield in tonnes per hectare $\left(\mathrm{tha}^{-1}\right)$, the farm area (ha), and the cost of irrigation water per cubic metre (rupees $\mathrm{m}^{-3}$ ). The cost of water in cubic metres was calculated by taking into account the cost of irrigation and the volume of water applied per hectare. The case study analyses focus on wheat. While both wheat and rice are grown in Sitapur, rice is not commonly cultivated in Jalaun, with only 1 farmer out of 50 interviewed growing the crop. The results of the analyses can be found in Figs. 2 to 6, with a description of results below.

\section{Case study - discussion and results}

\subsection{Quantitative results}

The results presented in Fig. 2 and in the maps in Figs. 3 and 4 show there is a significant variance in the irrigation practices of farmers in Jalaun and Sitapur. This can be seen in the volumes of irrigation water used (Fig. 2a), with farmers in Sitapur applying on average $1555 \mathrm{~m}^{3} \mathrm{ha}^{-1}$ more than farmers in Jalaun. This is also reflected in the overall cost of irrigation, with farmers in Sitapur paying on average over 7000 rupees ha $^{-1}$ season $^{-1}$ more to irrigate their wheat crop than their counterparts in Jalaun (Fig. 2b). This is despite the basic cost of water per cubic metre being largely the same: $3.58 \mathrm{r} \mathrm{m}^{-3}$ in Sitapur and $3.84 \mathrm{r} \mathrm{m}^{-3}$ in Jalaun (Fig. 2f).

Sitapur is by area one of the largest irrigators in Uttar Pradesh and for the most part relies on water from the underlying aquifers. The primary method of abstraction is by diesel pump, which, although reliable and versatile, is expensive, with farmers in Sitapur paying on average $12782 \mathrm{rha}^{-1}$ season ${ }^{-1}$ to irrigate their wheat crop. Jalaun, however, is one of the highest irrigators using canal water in Uttar Pradesh, with the majority of farmers interviewed (33/50) making use of the resource, often in conjunction with groundwater. This provides a cheap, and sometimes free, source of irrigation water (Figs. 2c and 3). In addition, farmers in Sitapur produce smaller yields than farmers in Jalaun, almost $2 \mathrm{tha}^{-1}$ less (Fig. 2d). As can be seen in Fig. $2 \mathrm{~b}$ and in Fig. 4, farmers in Sitapur apply $1017 \mathrm{~m}^{3}$ of irrigation water, with those in Jalaun using only $396 \mathrm{~m}^{3}$ to produce a tonne of wheat.

When comparing tube well users only in both districts, further differences emerged. In terms of production efficiency, farmers in Sitapur required an average of $1017 \mathrm{~m}^{3}$ of irrigation water per tonne of wheat produced, while their counterparts in Jalaun applied $800 \mathrm{~m}^{3}$ less (Fig. 5b). When only tube well users were taken into account, the price paid per cubic metre of irrigation water was found to be very different. Farmers in Sitapur paid an average of $3.58 \mathrm{rm}^{-3}$, whereas farmers in Jalaun pay significantly more: an average of $8.71 \mathrm{r} \mathrm{m}^{-3}$ (Fig. 5d). The fact that farmers applied less irrigation water in Jalaun, however (Fig. 5a), is reflected in 

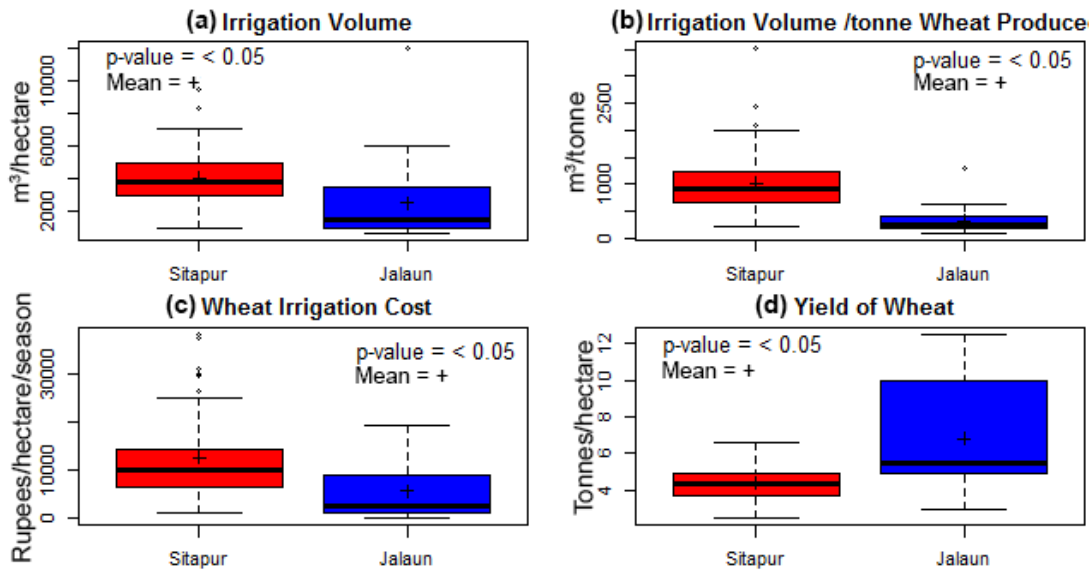

(d) Yield of Wheat

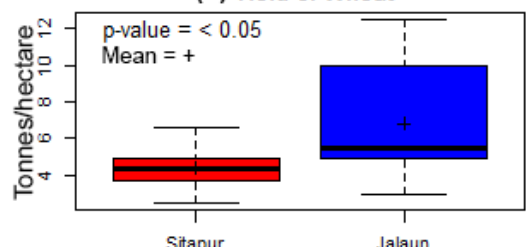

(e) Farm Size
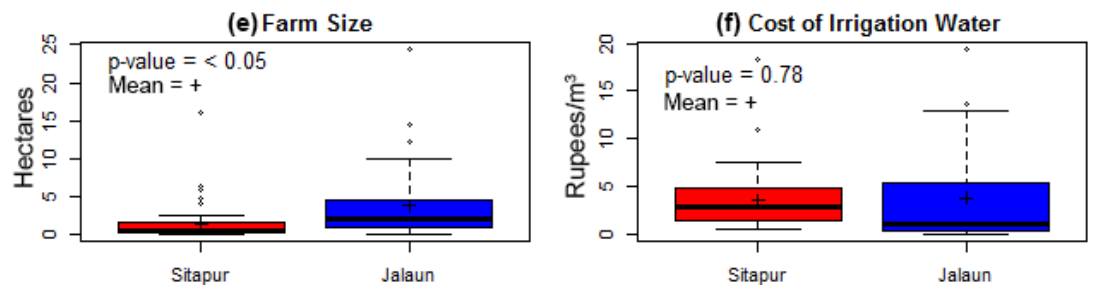

Figure 2. Differences in irrigation practices between the districts of Sitapur and Jalaun, Uttar Pradesh, northern India. The boxplots represent variability between farmers in each district. The boxes represent the 25 to 75 percentiles; the whiskers represent 1.5 times the interquartile range (IQR). The $P$ values give the chance of equal mean obtained from Student's $t$ test.

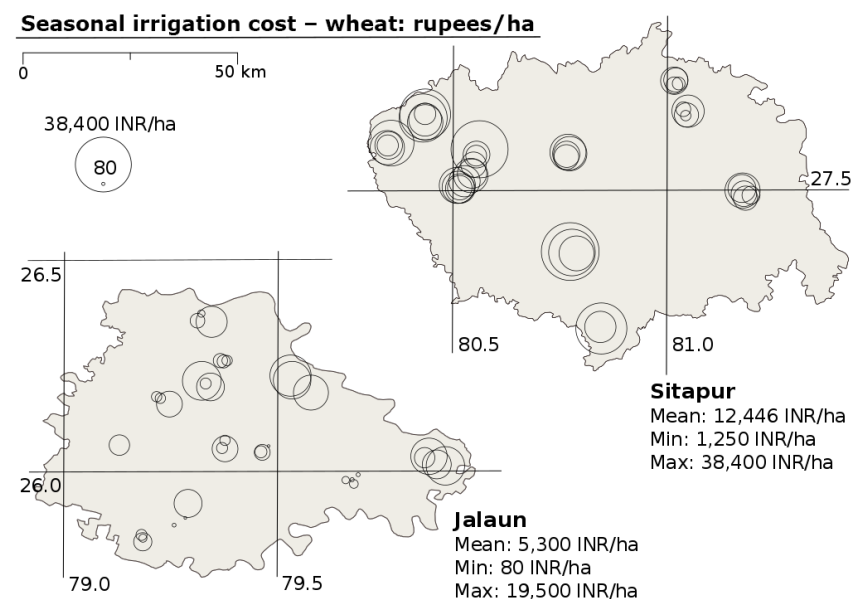

Figure 3. Spatial variations in the annual price paid for the irrigation of wheat by farmers in Jalaun and Sitapur, Uttar Pradesh, northern India.

the overall cost of irrigation by both groups (Fig. 5c). Farmers in Sitapur paid an average of $1167 \mathrm{rha}^{-1}$ more to irrigate their wheat crops despite the fact that the cost per cubic metre of water is less.

In Jalaun many of the interview participants had access to both tube wells and the cheaper but less reliable Irrigation Department-supplied canal water. Conjunctive use of surface and groundwater is often promoted as a realistic option to solving groundwater overdraft caused by irrigation (Harou

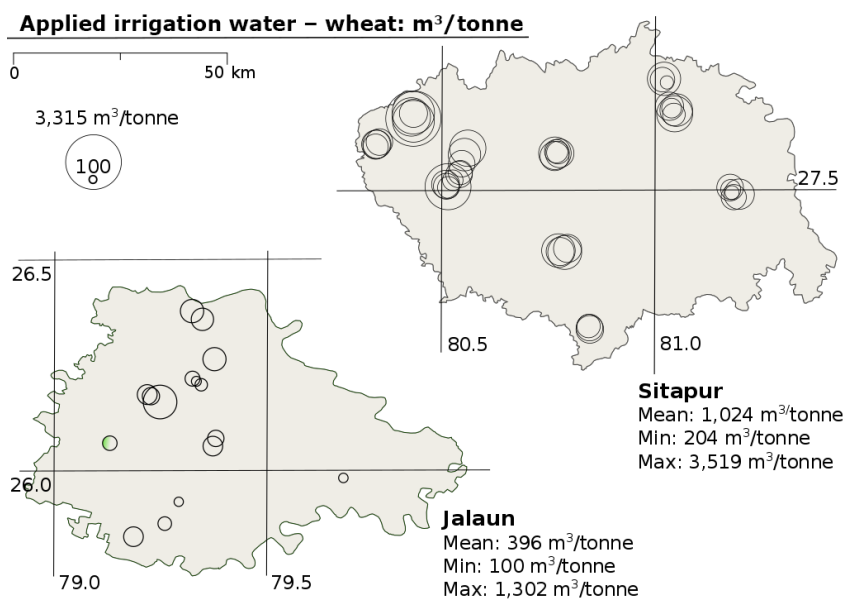

Figure 4. Spatial variations in the volume of water applied per tonne of wheat produced in Jalaun and Sitapur, Uttar Pradesh, northern India.

and Lund, 2008; Shah et al., 2008), and developing an understanding of farmer behaviour in this type of environment is important when formulating solutions. To investigate irrigation behaviour between farmers who have a choice in their water source (canal and tube well) and those who do not (tube well only), a comparison of the data collected within the district of Jalaun was undertaken, the results of which can be seen in Fig. 6. In terms of the volume of irrigation water applied, there was a statistically significant difference between 

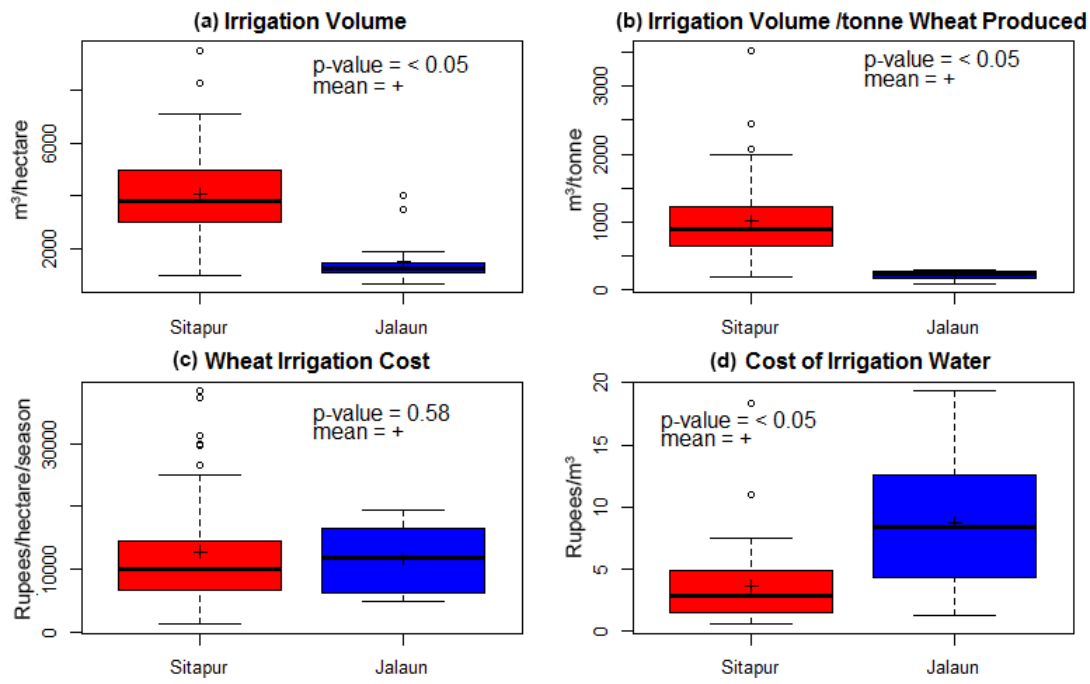

Figure 5. Differences in irrigation practices between tube well only users in the districts of Sitapur and Jalaun, northern India. The boxplots represent variability between farmers in each district. The boxes represent the 25 to 75 percentiles; the whiskers represent 1.5 times the interquartile range (IQR). The $P$ values give the chance of equal mean obtained from Student's $t$ test.
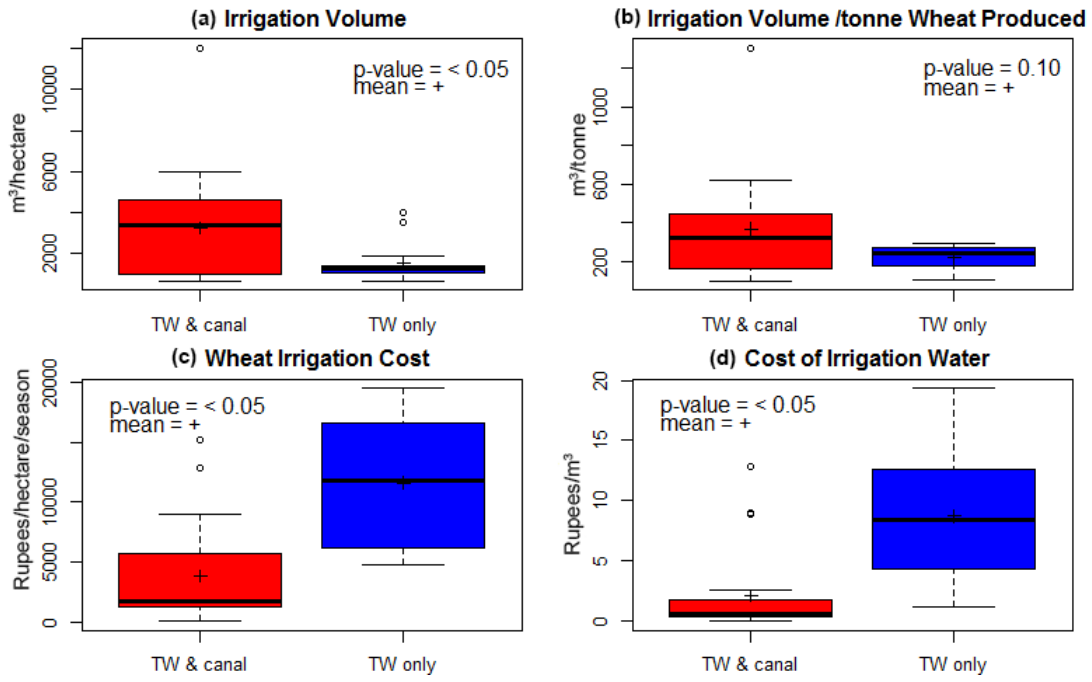

Figure 6. Differences in irrigation practices between tube well and canal users and canal-only users in the district of Jalaun, northern India. The boxplots represent variability between farmers in each district. The boxes represent the 25 to 75 percentiles; the whiskers represent 1.5 times the interquartile range (IQR). The $P$ values give the chance of equal mean obtained from Student's $t$ test.

both groups (Fig. 6a), with farmers who had canal access applying over $1722 \mathrm{~m}^{3}$ of water more than those who relied on tube wells only. While more water was used by farmers who have access to canals to produce $1 \mathrm{t}$ of wheat (Fig. 6b), the difference between the two groups was not found to be statistically significant. The cost of irrigation water however, per cubic metre, was found to be significantly different between both users (Fig. 6d); canal users paid an average of $2.09 \mathrm{r} \mathrm{m}^{-3}$, whereas farmers who use tube wells pay an average of $8.71 \mathrm{r} \mathrm{m}^{-3}$. As can be seen in Fig. 6c, in terms of the overall price paid for irrigation by both groups, farmers who had access to canal water were applying more, and also paid 7805 rupees ha $^{-1}$ season $^{-1}$ less to irrigate their wheat.

The data reported in this section provide an example of the type of information that can be collected using this methodology. While it reveals a considerable amount of detail on the irrigation behaviour of farmers in the region, it is envisaged that this information can be further utilised, particularly in the set-up and driving of hydro-economic and groundwater models of the region. 
Modelled (1948-2012) vs. reported (2013) wheat irrigartion water requirements

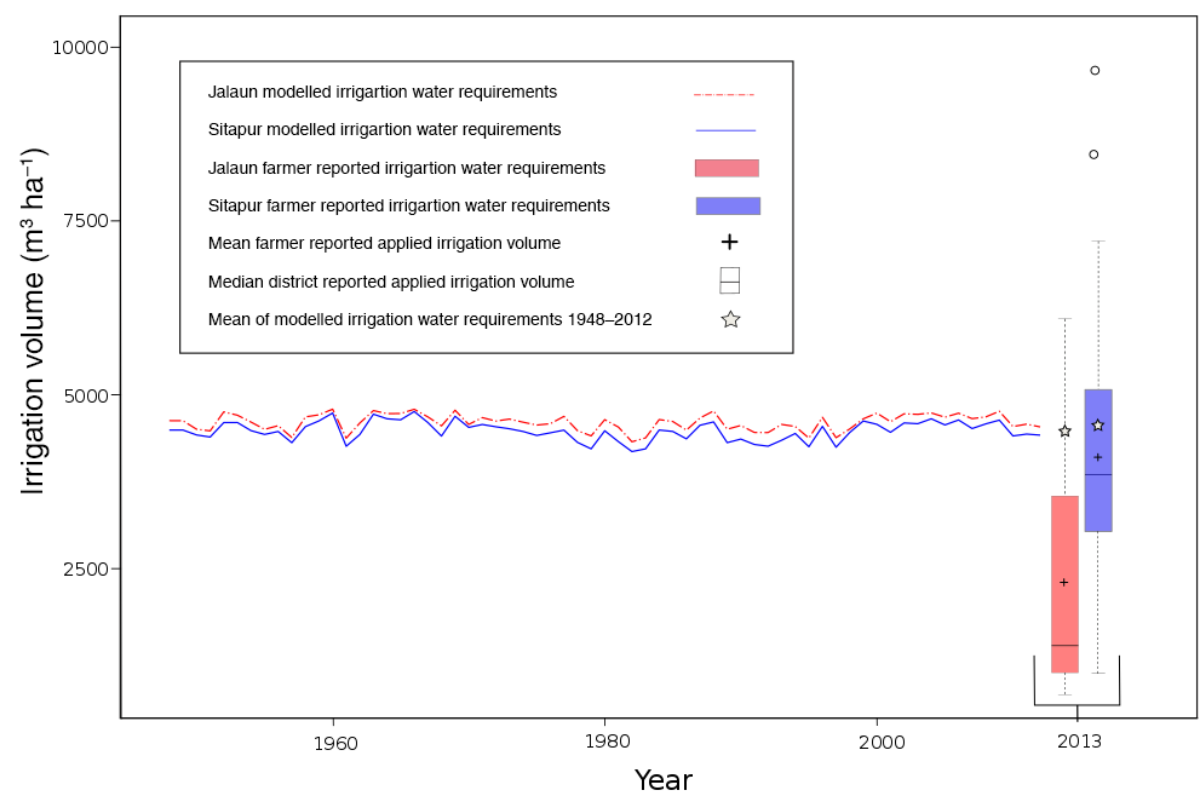

Figure 7. Differences between wheat irrigation volumes reported by farmers (boxplots) and modelled irrigation water requirements (time series). The mean modelled irrigation requirements from 1948 to 2012 are also shown (stars on boxplots) to aid comparison with 2013 reported information. The boxes represent the 25 to 75 percentiles; the whiskers represent 1.5 times the interquartile range (IQR). Circles represent outliers: values which exceed 1.5 times the IQR.

\subsection{Qualitative results}

The most commonly reported theme during the interviews was poor water availability. While no exact measurements were taken by respondents, a significant proportion in both districts reported that they had noticed water levels were falling. Among groundwater users, this was predominantly perceived to be as a result of overuse by other farmers and poor rainfall:

Farmer 1, Dafrapur, Sitapur. Translator: "Maybe because of many people extracting the water".

In some cases farmers reported that while they usually got water eventually, it was often too late to meet their crop water needs:

Farmer 1, Kishun Kheara, Sitapur. Translator: "Always get but not always on time".

This problem is exacerbated as water levels decrease during the post-monsoon season, causing farmers to rely on deeper tube wells, which are fewer in number, leading to a delay in access. A proportion of farmers in Sitapur highlighted that they had no issues with water supply when they had reliable access to a deep well or had land in an area with a high water table. Farmers in Sitapur are dependent on groundwater; however, many in Jalaun have access to both canal and surface water. Canals, while beneficial, particularly in terms of affordability, were perceived as unreliable, with the Irrigation Department-supplied water often arriving late or early for irrigation. This sometimes forced farmers to turn to the more expensive groundwater where available, to ensure their crops were irrigated. Indeed in Jalaun, the lack of access to a reliable water source was deemed to be the main reason for farmers' not growing rice, despite many saying that their soil was suitable:

Farmer 6, Barha Jalaun. Translator: "So he is telling me that he generally grows wheat, ... and don't grow rice because of lack of water, so soil is good for rice, but because of lack of water, they generally don't grow".

According to farmers in both districts, the lack of a dependable electricity supply was perceived as a significant barrier to accessing a sustainable source of water for irrigation. Electric submersible pumps allow for deeper water abstraction and are generally considered to be a cheaper option for farmers than the common diesel pump. Indeed the introduction or improving of electricity in an area was seen as an obvious solution to water issues in both districts. The fact that this could lead to further reductions in water levels was not mentioned by participants, highlighting the often myopic nature of farmers. Interviewees also singled out the Government for criticism, blaming them for poor infrastructure such as badly maintained wells, the poor electricity supply, and corruption: 
Farmer 2, Gulriha Sitapur. Translator: "He is saying government is not doing what they want here".

Farmer 1, Mania Sitapur. Interviewer: "And what do you think are the biggest problems you face at the moment?" Translator: "Lack of fertiliser, lack of water, lack of electricity everything what they say first is everything! Major thing is [government] corruption".

In Jalaun however, a number of farmers highlighted the benefits of some government policies, particularly that of free, or cheap, canal water. While welcome, farmers saw this practice as a means for local politicians to secure votes. As the participants were given freedom to elaborate where they saw fit, additional information emerged in a number of interviews. In Sitapur this included a system whereby access to water was shared between farmers who owned their own wells. This was outside the water market, a common method of irrigation water access in both districts, and was more prevalent in parts of Sitapur where farms were fragmented. The system allowed farmers to use tube wells owned by farmers neighbouring more distant pieces of their land, in return allowing their own well(s) to be used by others. Farmers would move their own pumps around to different wells as needed. A lack of labour was also highlighted as an issue for farmers. This emerged as an important reason why farmers did not use sprinklers for much of their wheat crop; while most were aware of the potential benefits, particularly in Jalaun, implementation was curtailed by the lack of available labour. Climate, particularly the lack of rainfall, emerged as a challenge for farmers; however a number of interviewees in Sitapur spoke of the onset of "Westerlies": a drying wind which had a dramatic effect on crop water requirements:

Farmer 3, Lilsi, Sitapur. Translator: "Because of Westerlies, the wind can carry more and more moisture from the soil".

Poor neighbour relations were highlighted as a potential problem in accessing water when needed in both districts but was more prevalent in Jalaun, particularly in terms of access to canal supply, with farmers further down the canal receiving less water. Interviewees also spoke of the damming of canals by farmers upstream as a problem in receiving water on time:

Farmer 4, Kusmra Bavani Jalaun. Translator: "...there is a conflict between the villages because the water distribution and what happens is that the upstream villagers they dam the canal as we have seen, and they stop the water for 2 or 3 days".

The perception among farmers in both districts was that irrigation water was not cheap. However, this did not appear to change their attitude to irrigation as a reduction in water could lead to a reduction in crop yield. It appeared that farmers were being as efficient as they could be, given the available resources.

\subsection{Comparison with modelled irrigation requirement results}

Crop water requirements can be estimated through various algorithms, for example Hargreaves-Samani (Hargreaves and Samani, 1985) or Penman-Monteith (Allen et al., 2005). These approaches are extremely useful as they can provide results without the need for field level measurements. It is important, however, to compare the modelled outputs to field data where possible as results can vary considerably. The reported volume of irrigation water applied by farmers to their wheat crop is compared to values obtained through modelling of requirements using HargreavesSamani' (Hargreaves and Samani, 1985) potential evapotranspiration method and the Terrestrial Hydrology Research Group at Princeton University's global meteorological forcing data set (Sheffield et al., 2006), the best data set for the region available for this study. The crop coefficients used in the calculation are provided by Chowdhury (2012), which are estimated through field experiments in northern India. These data allowed for the modelling of wheat irrigation requirements from 1948 to 2012. The results are then compared with irrigation volumes reported by farmers during fieldwork undertaken in 2013. All results are presented in Fig. 7. The model used the best available data set for the region; while the results do not overlap with reported values, the difference between modelled and information obtained in the field is clear.

The mean value reported by farmers in Sitapur is $4050 \mathrm{~m}^{3} \mathrm{ha}^{-1}$ of irrigation water applied during the wheat season. This is $368 \mathrm{~m}^{3} \mathrm{ha}^{-1}$ below the modelled 2012 result of $4418 \mathrm{~m}^{3} \mathrm{ha}^{-1}$. The difference in Jalaun is more significant, with a mean reported values of $2283,2253 \mathrm{~m}^{3} \mathrm{ha}^{-1}$ less than the modelled result of $4536 \mathrm{~m}^{3} \mathrm{ha}^{-1}$. The median reported values for both districts is also significantly lower than the modelled result (Jalaun: $1390 \mathrm{~m}^{3} \mathrm{ha}^{-1}$; Sitapur: $3800 \mathrm{~m}^{3} \mathrm{ha}^{-1}$ ), highlighting that the majority of farmers apply less water than would be predicted through modelling, showing the importance of using field-collected information to address model uncertainties. The variance found between the districts is likely due to differences in soil type with a higher proportion of sandy soil in Sitapur (Chauhan, 2007; Indian Council of Agricultural Research, 2010), requiring larger amounts of irrigation to maintain soil moisture. Rainfall rates are largely similar across both districts. The data reported in this section provide an example of the type of information that can be collected using this methodology. While it reveals a considerable amount of detail on irrigation behaviours, it is envisaged that this information can 
be further utilised, particularly in the set-up and driving of hydro-economic and groundwater models of the region.

\section{Opportunities and limitations of semi-structured interviews}

The lack of reliable quantitative and qualitative information is a major barrier in developing realistic water security options. In data-scarce regions of the world, information is typically downscaled from larger regional data sets; however this ignores the often significant spatial variability that exists on a finer scale. The use of qualitative as well as quantitative information is essential in identifying the drivers behind water use practices; however the collection of this information is often expensive and time-consuming. Semi-structured interviews provide a means of developing information-rich data sets in a time- and resource-efficient manner. Direct contact with water users and the opportunity to allow participants to expand on the issues of most importance to them provides a unique opportunity to develop an understanding of the human-water interface in a given location.

Despite the usefulness of semi-structured interviews, we identify some limitations in both the data collected and the approach used. The information collected, while useful for informing large-scale models, is most applicable to the scale at which it was collected, which ideally should coincide with a scale at which decisions on policy can be made and implemented: in this case district level. The type of data collected, both quantitative and qualitative, is useful for driving models, through numerical inputs and in setting rules - for example who has access to which water source and when. As can be seen in Sect. 4.3, the differences between modelled outputs and collected field data can be significant. Incorporating field level information where possible is an important consideration for modellers in order to highlight bias and uncertainty. This also applies to water users and water managers, as the approach allows for more realistic conclusions to be drawn from model outputs. In the case studies, interviews took place from September to November. This snapshot of the farming year in Uttar Pradesh is during a time of peak water availability, as it is following the monsoon season. It is possible that this influenced farmer responses. In addition, out of 105 farmers approached, only 5 declined to be interviewed. While this high participatory rate made fieldwork straightforward, it highlights a potential propensity for interviewees to please the interviewers, providing statements indicative of social desirability response bias (Collins et al., 2005), which may be reflected in the collected information. While social desirability response bias has been observed in Indian culture, it is not culturally specific (Hebert et al., 1998) and should be considered at all stages of data collection and analysis. In the case study reported above, interviews required the use of translators. Shortfalls associated with using a translator(s) are described in Kapborga and Berterö (2002); how- ever to limit the potential for discrepancy, training should be provided prior to fieldwork. It is also important to remember that in their environment the interviewee is the expert and should be treated as such. This also helps break down some of the barriers which may exist when a researcher and participant are from different cultures. It is important to take these factors into consideration at all stages of the research, including subsequent analyses. While the case study sample size ( $n=50$ per district) is small relative to the population (Sitapur $=623000$ farms, Jalaun $=253000$ farms; Uttar Pradesh State Planning Institute, 2012), we are confident that it presents a good representation of farming practices across the district as a whole. Verification of the objective accuracy of self-reported data is also an important consideration. Reported information can be triangulated with, if available, socio-economic data; outputs from other models; or, ideally, field level monitoring of water levels, abstraction rates, and surface water availability. While validation of collected data through objective measures is a necessary step in data collection, it is outside the scope of this paper. To address these shortcomings, further fieldwork should be undertaken, focusing on different regions of Uttar Pradesh during more waterscarce times of the year and, importantly, gaining objective measures of the data reported herein, i.e. via direct observation and metering of the phenomena. This would help in quantifying the differences between modelled, reported, and collected information, leading to more accurate hydrological model development and outputs, allowing for more realistic predictions to changes in boundary conditions, including those from climate change.

\section{Conclusions}

Limits in our current understanding of the human-water interface are a major constraint in developing options for future water security. One of the major barriers in developing this understanding is a lack of suitable qualitative and quantitative data. In this paper we present a methodology to facilitate the collection of information for hydrological and engineering purposes in data-scarce regions through semistructured interviews. We use this methodology to investigate farmer irrigation practices in the Ganges Basin of northern India, collecting information from 100 farmers across two districts. Information was obtained on topics such as irrigation water volumes, the cost of irrigation, water source, and the drivers behind these practices. Statistical analysis of the data, along with some data visualisation, is presented. Aspects such as a significant variability in water use practices, as well as insights into farmer behaviours and their environment, are highlighted. Semi-structured interviews provide a useful platform for the collection of qualitative and quantitative information simultaneously. This has clear benefits, including directly linking behaviours and their drivers to reported numerical values. Semi-structured interviews fa- 
cilitate the collection of detailed information quickly, easily, and relatively cost effectively while indicating themes which may not have been obvious beforehand, as well as highlighting aspects of the study which may no longer be relevant. The data collected also lend themselves to hydrological and hydro-economic modelling, as well as providing more realistic representations of user behaviour: an essential component in model development. While some limitations do exist, we are confident that this approach can be employed by natural scientists as an effective and efficient method of collecting both qualitative and quantitative hydrological information for the assessment of drivers, behaviours, and their outcomes in a data-scarce region.

\section{The Supplement related to this article is available online at doi:10.5194/hess-20-1911-2016-supplement.}

Acknowledgements. The authors would like to acknowledge the support of the NERC Changing Water Cycle (South Asia) project Hydrometeorological feedbacks and changes in water storage and fluxes in Northern India (grant number NE/I022558/1). The authors would also like to thank all reviewers for their constructive comments, which enabled us to significantly improve this paper.

Edited by: A. D. Reeves

\section{References}

Allen, R. G., Pereira, L. S., Raes, D., and Smith, M.: Crop evapotranspiration - Guidelines for computing crop water requirements - FAO Irrigation and Drainage Paper 56, Tech. rep., Food and Agriculture Organization of the United Nations, 1998.

Allen, R. G., I.Elliott, W. R. L., Howell, T. A., Itensfisu, D., Jensen, M. E., and Snyder L., R.: The ASCE Standardized Reference Evapotranspiration Equation, Tech. rep., The Task Committee on Standardization of Reference Evapotranspiration of the Environmental and Water Resources Institute, Reston, VA, USA, 2005.

Amarasinghe, U. A., Mccornick, P., and Shah, T.: Projections of irrigation water demand in India: What do recent trends suggest?, International Journal of River Basin Management, 7, 157-166, doi:10.1080/15715124.2009.9635378, 2009.

Avtar, R., Kumar, P., Singh, C. K., and Mukherjee, S.: A Comparative Study on Hydrogeochemistry of Ken and Betwa Rivers of Bundelkhand Using Statistical Approach, Water Quality, Exposure and Health, 2, 169-179, doi:10.1007/s12403-010-0035-2, 2011.

Barnes, A. P., McCalman, H., Buckingham, S., and Thomson, S.: Farmer decision-making and risk perceptions towards outwintering cattle, J. Environ. Manage., 129, 9-17, doi:10.1016/j.jenvman.2013.05.026, 2013.

Barriball, K. L. and While, A.: Collecting data using a semistructured interview: a discussion paper, J. Adv. Nurs., 19, 328 335, doi:10.1111/j.1365-2648.1994.tb01088.x, 1994.
Burnard, P., Gill, P., Stewart, K., Treasure, E., and Chadwick, B.: Analysing and presenting qualitative data, Brit. Dent. J., 204, 429-432, doi:10.1038/sj.bdj.2008.292, 2008.

Calheiros, D., Seidl, A., and Ferreira, C.: Participatory research methods in environmental science : local and scientific knowledge of a limnological phenomenon in the Pantanal wetland of Brazil, J. Appl. Ecol., 37, 684-696, doi:10.1046/j.13652664.2000.00524.x, 2000.

Chauhan, P.: Ground Water Brochure of Sultanpur District, Uttar Pradesh, Tech. Rep. May 2007, 2007.

Chowdhury, N. T.: Irrigation Institutions of Bangladesh: Some Lessons. Problems, Perspectives and Challenges of Agricultural Water Managment, http://www.intechopen.com/books/problems-perspectivesand-challenges-ofagricultural-water-management/irrigationinstitutions-of-bangladesh-some-lessons (last access: 19 November 2015), 2012.

Collins, M., Shattell, M., and Thomas, S. P.: Problematic interviewee behaviors in qualitative research, Western J. Nurs. Res., 27, 188-99; discussion 200-9, doi:10.1177/0193945904268068, 2005.

Creswell, J. W.: Research Design. Qualitative, Quantitative, and Mixed Methods Approaches, SAGE Publications Ltd, 3rd edn., doi:10.1002/1521-3773(20010316)40:6<9823::AIDANIE9823>3.3.CO;2-C, 2009.

Döll, P. and Siebert, S.: Global modeling of irrigation water requirements, Water Resour. Res., 38, 1-10, doi:10.1029/2001WR000355, 2002.

Döll, P., Müller Schmied, H., Schuh, C., Portmann, F. T., and Eicker, A.: Global-scale assessment of groundwater depletion and related groundwater abstractions: Combining hydrological modeling with information from well observations and GRACE satellites, Water Resour. Res., 50, 5698-5720, doi:10.1002/2014WR015595, 2014.

Ellis, L. M. and Chen, E. C.: Negotiating identity development among undocumented immigrant college students: a grounded theory study, J. Couns. Psychol., 60, 251-64, doi:10.1037/a0031350, 2013.

Fallon, P.: Life events; Their role in onset and relapse in psychosis, research utilizing semi-structured interview methods, J. Psychiatr. Ment. Hlt., 15, 386-392, doi:10.1111/j.13652850.2007.01244.x, 2008.

Famiglietti, J. S.: The global groundwater crisis, Nature Climate Change, 4, 945-948, doi:10.1038/nclimate2425, 2014.

Fenicia, F., Kavetski, D., and Savenije, H. H. G.: Elements of a flexible approach for conceptual hydrological modeling: 1. Motivation and theoretical development, Water Resour. Res., 47, doi:10.1029/2010WR010174, 2011.

Flick, U.: An introduction to qualitative research, vol. 9781446267, London, Sage Publications, London, 5 edn., 2014.

Gao, H., Birkett, C., and Lettenmaier, D. P.: Global monitoring of large reservoir storage from satellite remote sensing, Water Resour. Res., 48, 1-12, doi:10.1029/2012WR012063, 2012.

GEWEX: GEWEX Plans for 2013 and Beyond - GEWEX Science Questions (Version 1), Tech. Rep. GEWEX Document Series No. 2012-2, GEWEX, http://www.gewex.org/gewex-content/ uploads/2015/02/GEWEX_Science_Questions_final.pdf (last access: 19 November 2015), 2012. 
Gibson, C.: Semi-structured and unstructured interviewing - a comparison of methodologies in research with patients following discharge from an acute psychiatric hospital, J. Psychiatr. Ment. Hlt., 5, 469-477, doi:10.1046/j.1365-2850.1998.560469.x, 1998.

Government of India: Census 2011 - Provisional Population Totals, Tech. rep., Ministry of Home Affairs, 2011.

Guarte, J. M. and Barrios, E. B.: Computation Estimation Under Purposive Sampling, Communications in Statistics - Simulation and Computation, 0918, 277-284, doi:10.1080/03610910600591610, 2006.

Hagirath, B., Kumar, C., Nauriyal, D. K., Nayak, N. C., Prasad, P. M., Rajgopalan, P., Mishra, P., Trivedi, P. L., Agrawal, A., Singh, S. P., Sharma, S., Mazumder, T. N., Upadhyay, V. B., Sharma, V., and Tare, V.: Trends in Agriculture and Agricultural Practices in Ganga Basin. An Overview, Tech. rep., Ganga River Basin Managment Plan, 2011.

Hargreaves, G. H. and Samani, Z. A.: Reference Crop Evapotranspiration From Ambient Air Temperature, Paper - American Society of Agricultural Engineers, 96-99, http://www.scopus. com/inward/record.url?eid=2-s2.0-0022284023\&partnerID= 40\&md5=8dbbb2b21fcf0b47f0fb6d1e5dcefa02 (last access: 19 November 2015), 1985.

Harou, J. J. and Lund, J. R.: Ending groundwater overdraft in hydrologic-economic systems, Hydrogeol. J., 16, 1039-1055, doi:10.1007/s10040-008-0300-7, 2008.

Hebert, J. R., Gupta, P. C., Bhonsle, R. B., Sinor, P. N., Mehta, H., and Mehta, F. S.: Development and testing of a quantitative food frequency questionnaire for use in Gujarat, India, Public Health Nutr., 2, 39-50, doi:10.1017/S1368980099000051, 1998.

Huang, R.: RQDA: R-based Qualitative Data Analysis, http://rqda. r-forge.r-project.org/ (last access: 8 September 2015), 2014.

ICRISAT-ICAR-IRRI: Village Dynamics in South Asia (VDSA), District Level Database Documentation, Tech. rep., ICRISATICAR-IRRI Collaborative Research Project, 2012.

Indian Council of Agricultural Research: District Profile: Uttar Pradesh, Tech. rep., Indian Council of Agricultural Reseasrch - Zonal Project Directorate Kanpur, http://zpdk.org.in/sites/ default/files/districtprofile(2-2-10).pdf (last access: 14 March 2016), 2010.

Jewitt, S. and Baker, K.: The Green Revolution re-assessed: Insider perspectives on agrarian change in Bulandshahr District, Western Uttar Pradesh, India, Geoforum, 38, 73-89, doi:10.1016/j.geoforum.2006.06.002, 2007.

Kapborga, I. and Berterö, C.: Using an interpreter in qualitative interviews: does it threaten validity?, Nurs. Inq., 9, 52-6, http: //www.ncbi.nlm.nih.gov/pubmed/12164715, 2002.

Mason, J.: Qualitative Researching, SAGE Publications Ltd, London, second edn., doi:10.1016/S0143-6228(97)90005-9, 2002.

McKenney, M. S. and Rosenberg, N. J.: Sensitivity of some potential evapotranspiration estimation methods to climate change, Agr. Forest Meteorol., 64, 81-110, doi:10.1016/01681923(95)02240-X, 1993.

Ministry of Panchayati Raj: Backward Regions Grant Fund Programme, http://www.panchayat.gov.in/details-of-brgf-districts (last access: 29 October 2015), 2014.

Montanari, A.: Debates - Perspectives on sociohydrology: Introduction, Water Resour. Res., 51, 2-31, doi:10.1002/2015WR017430, 2015.
Mottram, A.: "They are marvellous with you whilst you are in but the aftercare is rubbish": a grounded theory study of patients' and their carers' experiences after discharge following day surgery, J. Clin. Nurs., 20, 3143-51, doi:10.1111/j.13652702.2011.03763.x, 2011.

Mueller, N. D., Gerber, J. S., Johnston, M., Ray, D. K., Ramankutty, N., and Foley, J. A.: Closing yield gaps through nutrient and water management, Nature, 490, 254-257, doi:10.1038/nature11420, 2012.

Nazemi, A. and Wheater, H. S.: On inclusion of water resource management in Earth system models - Part 1: Problem definition and representation of water demand, Hydrol. Earth Syst. Sci., 19, 33-61, doi:10.5194/hess-19-33-2015, 2015a.

Nazemi, A. and Wheater, H. S.: On inclusion of water resource management in Earth system models - Part 2: Representation of water supply and allocation and opportunities for improved modeling, Hydrol. Earth Syst. Sci., 19, 63-90, doi:10.5194/hess19-63-2015, $2015 b$.

Portmann, F. T., Siebert, S., and Döll, P.: MIRCA2000 - Global monthly irrigated and rainfed crop areas around the year 2000: A new high-resolution data set for agricultural and hydrological modeling, Global Biogeochem. Cy., 24, 1-24, doi:10.1029/2008GB003435, 2010.

Rabionet, S. E.: How I Learned to Design and Conduct Semistructured Interviews : An Ongoing and Continuous Journey, The Qualitative Report, 16, 563-566, http://www.nova.edu/ssss/QR/ QR16-2/rabionet.pdf (last access: 16 January 2015), 2011.

Rodell, M., Velicogna, I., and Famiglietti, J. S.: Satellite-based estimates of groundwater depletion in India., Nature, 460, 999-1002, doi:10.1038/nature08238, 2009.

Shah, T., Bhatt, S., Shah, R., and Talati, J.: Groundwater governance through electricity supply management: Assessing an innovative intervention in Gujarat, western India, Agr. Water Manage., 95, 1233-1242, doi:10.1016/j.agwat.2008.04.006, 2008.

Sheffield, J., Goteti, G., and Wood, E. F.: Development of a 50-year high-resolution global dataset of meteorological forcings for land surface modeling, J. Climate, 19, 3088-3111, doi:10.1175/JCLI3790.1, 2006.

Siebert, S. and Döll, P.: Quantifying blue and green virtual water contents in global crop production as well as potential production losses without irrigation, J. Hydrol., 384, 198-217, doi:10.1016/j.jhydrol.2009.07.031, 2010.

Singh, N. J., Kudrat, M., Jain, K., and Pandey, K.: Cropping pattern of Uttar Pradesh using IRS-P6 (AWiFS) data, Int. J. Remote Sens., 32, 4511-4526, doi:10.1080/01431161.2010.489061, 2011.

Singh, R.: Environmental consequences of agricultural development: a case study from the Green Revolution state of Haryana, India, Agr. Ecosyst. Environ., 82, 97-103, doi:10.1016/S01678809(00)00219-X, 2000.

Tiwari, V. M., Wahr, J., and Swenson, S.: Dwindling groundwater resources in northern India, from satellite gravity observations, Geophys. Res. Lett., 36, L18401, doi:10.1029/2009GL039401, 2009.

Uttar Pradesh State Planning Institute: Statistical Abstract of Uttar Pradesh 2012, http://updes.up.nic.in, Tech. rep., Economics and Statistics Division, State Planning Institute, Uttar Pradesh, 2012.

Voss, K. A., Famiglietti, J. S., Lo, M., De Linage, C., Rodell, M. and Swenson, S. C.: Groundwater depletion in the Middle East 
from GRACE with implications for transboundary water management in the Tigris-Euphrates-Western Iran region, Water Resour. Res., 49, 904-914, doi:10.1002/wrcr.20078, 2013.

Wada, Y., Van Beek, L. P. H., Van Kempen, C. M., Reckman, J. W. T. M., Vasak, S., and Bierkens, M. F. P.: Global depletion of groundwater resources, Geophys. Res. Lett., 37, 1-5, doi:10.1029/2010GL044571, 2010.

Winsemius, H. C., Schaefli, B., Montanari, A., and Savenije, H. H. G.: On the calibration of hydrological models in ungauged basins: A framework for integrating hard and soft hydrological information, Water Resour. Res., 45, W12422, doi:10.1029/2009wr007706, 2009.
Wisser, D., Frolking, S., Douglas, E. M., Fekete, B. M., Vörösmarty, C. J., and Schumann, A. H.: Global irrigation water demand: Variability and uncertainties arising from agricultural and climate data sets, Geophys. Res. Lett., 35, 1-5, doi:10.1029/2008GL035296, 2008. 